\title{
Modeling Enterprise Interoperability: Taming the Information Explosion
}

\author{
Richard Mark Soley \\ Object Management Group, Inc. \\ 109 Highland Avenue, Needham, MA 02494, U.S.A. \\ soley@omg.org
}

\begin{abstract}
The problems of enterprise interoperability, portability, maintenance and integration are not exactly new. From the first time code was stored in memory, the problems of legacy integration with new users and new uses of computing systems began. The explosion of computing vendors and tools hasn't exactly made the problem any easier. In fact, it's the explosion of information in general that is causing the problem. We expect information at our fingertips, but somehow we expect that to come about magically, despite different developers, different development styles, different coding languages, operating systems, instruction set architectures -- and a general lack of planning (or indeed, reading of the literature). The most important problem is the enormous explosion of information available in the world, and the increasing demands for globalized, mobile, agile, connected business processes across newly digital value chains. The resulting complexity makes integration even harder than it was before -and it was near impossible before. There is some hope, however. That hope is formal modeling, with associated metrics and continuous improvement of processes based on customer and supplier feedback. That is much easier to achieve, however, when those business models are "live" -- that is, rather than simply documenting the business process, they in fact are the business process. This requires not only formal models, but formal models with well-defined semantics. The combination of Business Process Modeling (BPM) with Model Driven Architecture (MDA) promises just that. This keynote will discuss the driving factors for BPM and MDA, and the standards that support the approach.
\end{abstract}

Keywords: Enterprise Interoperability, information explosion, Business Process Modeling, Model Driven Architecture.

\section{Brief Biography}

Richard Mark Soley, Ph.D is Chairman and CEO of the Object Management Group, Inc. (OMG). Dr. Soley was instrumental in the founding of OMG in 1989 (as the founding Chief Technology Officer), and since 1997 has led the organization as Chief Executive Officer.

As CEO, Dr. Soley is responsible for the vision and direction of the world's largest consortium of its type. After joining the nascent organization in 1989, Dr. Soley led the development of OMG's world-leading standardization process and the original 
CORBA $®$ specification. In 1996, he led the effort to move into vertical market standards (starting with healthcare, finance, telecommunications and manufacturing) and modeling, leading first to the Unified Modeling Language ${ }^{\mathrm{TM}}$ (UML®) and later the Model Driven Architecture ${ }^{\circledR}($ MDA $®$ ). He also led the effort to establish the SOA Consortium in January 2007, leading to the launch of the Business Ecology Initiative (BEI) in 2009. The Initiative focused on the management imperative to make business more responsive, effective, sustainable and secure in a complex, networked world, through practice areas including Business Design, Business Process Excellence, Intelligent Business, Sustainable Business and Secure Business. In addition, Dr. Soley is the Executive Director of the Cloud Standards Customer Council, helping end-users transition to cloud computing and direct requirements and priorities for cloud standards throughout the industry. He was also directly involved in the creation of both the Eclipse Foundation and Open Health Tools.

Since 1989, OMG has become one of the world leaders in the creation of international software industry standardization, building worldwide communities to deliver software standards that have changed the face of the software development field. Hundreds of member companies (approximately half software vendors and half software users, with government agencies \& research institutions as well), volunteering thousands of product management and software development professionals, are currently developing some hundred software standards in fields as diverse as business processing modeling languages \& methodologies, systems modeling languages, cloud computing, software modernization \& real-time \& embedded systems, but also vertically-oriented standards in financial services, insurance, healthcare, manufacturing, life sciences, military command \& control, military \& civil communications, civil government management and new areas like smart energy grids and systems safety assurance for consumer devices from automobiles to consumer electronics.

In more than two decades at OMG, Dr. Soley has led the development of a leadership community on the OMG Board of Directors that has included high-level executives from IT vendors including IBM, Hewlett Packard, Oracle and Microsoft but also key vertical-market leaders like THALES, Citigroup, HSBC, Lockheed Martin, Northrop Grumman, John Deere \& Company and many others, including many small and medium-sized firms as well. Through relationships around the world, Dr. Soley has become quite well known in the speaking circuit, giving hundreds of speeches in support of OMG's best-practices \& technology programs in North \& South America, all over Asia, Europe, Africa and the Middle East, on issues relevant to standards, the adoption of new technology and creating successful companies. Dr. Soley also serves on numerous industrial, technical and academic conference program committees all over the world. Before helping to found OMG, Dr. Soley was a successful entrepreneur, participating in and leading startups in the computer software and hardware arena. Start-up companies included A.I. Architects (the first leader in acceleration hardware for personal computers, and originator of the DOS extender), Symbolics (the most successful start-up in artificial intelligence hardware \& software), PictureTel (the early leader in video telephony, now part of Polycom) and many others. Dr. Soley continues this early entrepreneurial focus with an active participation in venture investment $\&$ advising, with companies including United 
Villages (the leader in rural delivery of fast-moving consumer goods in India, with a recent partnership with Oxigen), rollApp (a Ukrainian/US leader in rapid application virtualization for cloud delivery), Polymita (a Spanish company which was focused on being the world leader in business process automation, recently sold to Red Hat), Strategic Security Air (delivering lightweight, long-endurance, low-cost surveillance aircraft for civil and light military usage), ProcessUnity (a world leader in business process modeling for regulatory compliance and other innovative risk solutions), SpaceCurve (the leader in real-time geospatial-temporal databases for location services), ClinicalBox (the leader in automated surgical coordination), and so forth.

A native of Baltimore, Maryland, U.S.A., Dr. Soley's academic background includes the SB, SM and $\mathrm{PhD}$ degrees in Computer Science \& Engineering from MIT, with undergraduate minor in Spanish and graduate concentration in business (with coursework from MIT's Sloan School and Harvard Law School). Dr. Soley has continued his academic \& research relationships worldwide with associations as an advisor, Visiting Professor or Adjunct Professor at the Curtin University in Perth, Australia, Colorado State University, Wuhan University in the People's Republic of China, Bentley College near Boston, the Software Engineering Methods and Tools (SEMAT) international project, Fraunhofer Institut für Software- und Systemtechnik in Berlin, Goethe Universität Frankfurt am Main and others. Dr. Soley is a Life Member of the national engineering honor fraternity Tau Beta Pi; a Member of the national electical engineering honor fraternity Eta Kappa $\mathrm{Nu}$, and a Life Member of the scientific research honor fraternity Sigma Xi, as well as a member of AAAI, ACM and IEEE; he is also a Founding Member of the Boston CTO Club, and a Member of the New York City CTO Club. 